\title{
Voltaire, Dictionnaire philosophique
}

\section{Franco Piva}

\section{(2) OpenEdition}

\section{Journals}

\section{Edizione digitale}

URL: http://journals.openedition.org/studifrancesi/5637

DOI: 10.4000/studifrancesi.5637

ISSN: 2421-5856

\section{Editore}

Rosenberg \& Sellier

\section{Edizione cartacea}

Data di pubblicazione: 1 septembre 2011

Paginazione: 411-412

ISSN: 0039-2944

\section{Notizia bibliografica digitale}

Franco Piva, «Voltaire, Dictionnaire philosophique», Studi Francesi [Online], 164 (LV | II) | 2011, online dal 30 novembre 2015, consultato il 07 janvier 2021. URL: http://journals.openedition.org/studifrancesi/ 5637 ; DOI: https://doi.org/10.4000/studifrancesi.5637

\section{Questo documento è stato generato automaticamente il 7 janvier 2021.}

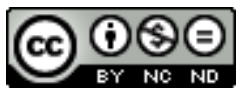

Studi Francesi è distribuita con Licenza Creative Commons Attribuzione - Non commerciale - Non opere derivate 4.0 Internazionale. 


\title{
Voltaire, Dictionnaire philosophique
}

\author{
Franco Piva
}

\section{NOTIZIA}

volTAIRE, Dictionnaire philosophique, Présentation, notes, choix de variantes, annexe, chronologie, bibliographie, index par Gerhardt STENGER, Paris, GF-Flammarion, 2010, $634 \mathrm{pp}$.

1 Il Dictionnaire philosophique è certamente, dopo Candide, uno dei titoli dell'immensa produzione voltairiana più frequentemente citati; non è detto che sia anche una delle sue opere più spesso lette, pur meritandolo ampiamente. Non tanto perché esso rappresenti, in dimensioni tutto sommato contenute, una delle più belle sintesi del pensiero voltairiano, quanto perché propone all'attenzione dei suoi lettori alcuni dei problemi che più hanno suscitato l'attenzione e la riflessione di Voltaire in un momento particolarmente importante e difficile della sua lunga carriera di uomo e di philosophe: quello che segue la sua decisione di installarsi a Ferney e di investirsi con ancora maggiore intensità di quanto non avesse fatto fino ad allora in alcune delle questioni più cruciali della sua epoca; alcuni faits-divers (le condanne a morte del vecchio Jean Calas e del giovane chevalier de la Barre) che hanno fortemente interessato la sensibilità, inducono infatti Voltaire, che non ha trovato soddisfacente il modo in cui le rispettive inchieste sono state condotte, ad affrontare, su basi nuove, quello che diventerà per lui una sorta di chiodo fisso: la lotta contro il fanatismo religioso e, quindi, il rapporto tra la religione e la vita degli uomini e degli stati. Quello della tolleranza è un problema che non investe solo opere come il quasi coevo Traité sur la tolérance, nato direttamente dall'affaire Calas, ma che costituisce il filo conduttore anche del Dictionnaire philosophique, opera nella quale la riflessione di Voltaire si fa anzi più ampia ed investe il ruolo stesso della religione nella società degli uomini, di quella cristiana soprattutto, che, ritenuta responsabile e fonte primaria, per la sua pretesa universalistica, di intolleranza, è la più fortemente visée, e sulla quale insiste in effetti molto (fors'anche troppo) nella sua lunga e bella «Présentation» Gerhardt Stenger, che per i «GF Flammarion» ha già curato in anni recenti l'edizione delle Lettres 
philosophiques e dei Derniers écrits sur Dieu, a segno del suo interesse per un tema certamente essenziale ma non esclusivo nell'opera di Voltaire.

2 La lettura di Stenger trova la sua spiegazione, se non sempre anche la sua giustificazione, nell'intenzione di far scoprire ad un pubblico vasto, e spesso giovanile, quale quello dei «GF», l'attualità della riflessione di Voltaire e dei problemi con i quali la sua riflessione ha dovuto fare i conti, in particolare con la pretesa delle religioni, e di alcune di esse in particolare (a quella cristiana è succeduta recentemente quella islamica) di sostituirsi allo Stato nella conduzione dell'uomo e nella identificazione del bene e del male all'interno della società civile; e, per certi versi anche, nella volontà che animò Voltaire nella composizione dell'opera: non si trattava infatti per lui di fare l'ennesimo Dictionnaire con il quale jouer d'érudition con i suoi concorrenti, bensì di scrivere un'opera che potesse interessare il maggior numero di lettori, in particolare quelli che all'epoca si chiamavano gli honnêtes gens. Per raggiungere questo scopo era necessario che l'opera, oltre che utile, fosse anche gradevole; ed è su questo aspetto, e su questa novità che Stenger attira giustamente, in un'altra parte della sua «Présentation», l'attenzione del lettore moderno. «Docere et placere, instruire et amuser, telle est bien la devise affichée du Dictionnaire philosophique. Le public qu'il vise se compose, pour l'essentiel, de beaux esprits et de lettrés qui cherchent l'agrément et refusent la pedanterie, c'est à dire la spécialisation du savoir et le jargon concomitant. Voltaire en a profondément coscience: "Je me dis toujours, il faut tâcher qu'on te lise sans dégoût; c'est par le plaisir qu'on vient à bout des hommes". Tout en utilisant l'érudition (assai più solida - sia detto en passant - di quanto si è spesso detto), il s'en joue pour souligner à quel point il est éloigné de la troupe ennuyeuse des pédants, parce que "tout honnête homme doit chercher à être philosophe, sans se piquer de l'être". La plupart des articles du Dictionnaire philosophique, écrits sous forme d'anecdote, de fable, d'allégorie, de songe, de Discours, de dialogue, de série de questions ou même de note de lecture et de dissertation savante sont imprégnés de cet esprit de conversation dans lequel le XVIII ${ }^{\mathrm{e}}$ siècle était passé maître. De cette manière, Voltaire a réussi à hisser le genre banal du dictionnaire au rang du chef-d'œuvre de la littérature d'idées du siècle des Lumières».

3 Una sottolineatura non solo giusta, quella di Stenger, ma anche opportuna. La popolarità di cui il Dictionnaire ha goduto fin dal xvIII secolo, e di cui ancora oggi gode, proviene non soltanto dall'importanza e dall'attualità della lotta condotta dal suo autore contro ogni forma di fanatismo e di intolleranza religiosa, ma anche dallo stile posto in atto da Voltaire in quest'opera: «la hardiesse et l'originalité des idées exprimées servies par la prose voltairienne - fa ancora notare Stenger - constituent un mélange explosif que les "ennemis de la raison" (dixit Voltaire) ont immédiatement perçu». Il Dictionnaire philosophique, oltre che un'accorata difesa di ciò che rende la vita umana degna di essere vissuta in qualunque tempo ed in qualunque luogo, costituisce quindi anche un'attualissima lezione di strategia discorsiva, di cui non sarebbe male che certi scrittori o intellettuali d'oggi tenessero debito ed umile conto. 